\title{
Moving closer. A Conversation Analytic Perspective on how a Psychotherapeutic Dyad Works on Closing their Encounters
}

\author{
Michael M. Dittmann ${ }^{1}$ \\ International Psychoanalytic University (IPU)
}

\begin{abstract}
This pilot study analyzes a blank space of research: How is the actual therapeutic session closed and how do single closings contribute to the over-all process of therapy? Data corpus is a completely transcribed single short-term psychodynamic psychotherapy. All 28 closing sequences were fully analyzed with Conversation Analysis. The over-all structure of therapy is unfolded in closings in three ways: i) as a joint activity with 'audible' steps, describable as scheme of closing, ii) as alignment organization that reveals three closing types: compact, stretched and commented closings. (These types can be seen as manifest realizations of an implicit communicative problem, the coda dilemma: How to close a session with open topics?) And iii) thirdly, therapist and patient typically display their interactional affiliation towards the therapeutic process with joint evaluation of therapeutic help (JETH). Clinical relevant learnings of this study are: i) closing section is to be unilaterally initiated by the therapist while the patient actively suppresses open topics, ii) therapist has deontic authority only and his action is subject to approval, iii) psychotherapeutic dyad establishes a social relationship by projecting closing and iv) therapy is co-actively and locally produced when expansions after closings are taken as a comment on the therapeutic situation.
\end{abstract}

"Ending is ever present, long before the final separation, casting its shadow on therapy from the start and, when it comes, is a culmination of all the countless little endings that have prefigured it. In Rilkes words, 'So we live, forever taking leave', (Holmes, 1997, p. 170).

\section{Introduction}

The fringes of therapy have been an important field of psychoanalytic research: How to start the first therapeutic session(s), as well as initiating the termination of therapy. But there is a blank space of research on closing the actual therapeutic encounter. The present study analyzes how a psychotherapeutic dyad manages to open up, conduct and terminate the closing section of a therapeutic encounter. Conversation Analysis is applied to $28^{1}$ GAT transcriptions of a single short-term psychodynamic psychotherapy from the

${ }^{1}$ Correspondence concerning this article should be addressed to Michael Dittmann, International Psychoanalytic University (IPU), Stromstr. 3b. 10555 Berlin, Germany. E-mail: michael.dittmann@ipu-berlin.de.

${ }^{1}$ Because session 23 was cancelled, numerical there are 29 sessions, but indeed just 28 conducted treatments.

Language and Psychoanalysis, 2016, 5 (2), 46-61

http://dx.doi.org/10.7565/landp.v5i2.1560 
1980s with an obsessive-compulsive patient. The focus of the study is on the actual closing section of each therapeutic encounter, and a single-case over-all process of closing therapeutic sessions. The short-term therapy is divided into three thirds (see Figure 1) i) the beginning sessions (1-9), ii) the mid sessions (10-18), iii) the end sessions (19-28) and the last session (29).

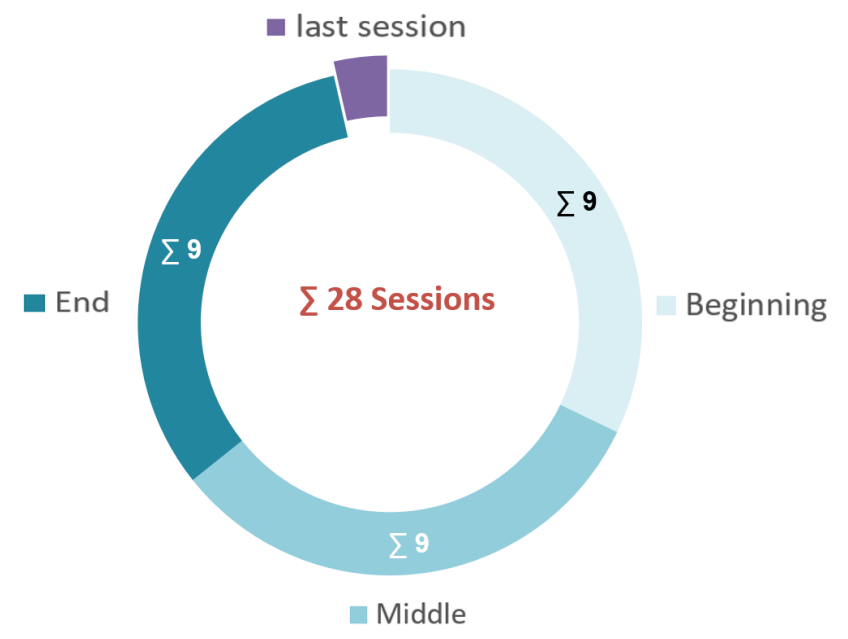

Figure 1

Segments of short-term therapy

\section{Mundane Closing}

Before we turn to closing in an institutional therapeutic setting, there are some essentials on closing that are prefigurative to institutional closing. In their classical contribution to closing mechanisms in conversations, (Schegloff \& Sacks, 1973) paid attention to closing sections in everyday talk and identified a problem in closing: When does 'not talking' close down a conversation and is, therefore, no Transition Relevant Place (TRP)? They detected that participants do not just stop talking but co-produce the suspension of TRP with exclusive markers such as adjacency pairs. In their "minimal scheme" (Raitaniemi, 2014, p. 73) the exchange of these adjacency pairs like "bye" at the end of conversations is called terminal component (see lines 3 and 4 in Figure 2). But these exclusive markers cannot be placed in every moment, that is why participants i) increase the relevance of closing and ii) try to verify if the co-participant wants to continue talking. This negotiation procedure is called pre-closing component (see lines 1 and 2 in Figure 2), because topic talk can be re-opened or closed. Contrasting with mundane closing, how do therapist and patient open up the closing process of therapeutic encounters? 


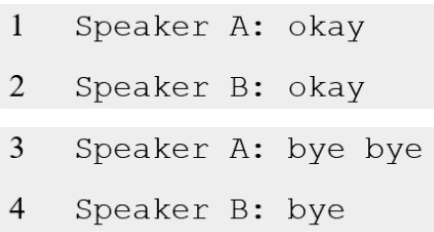

Figure 2

\section{Minimal scheme}

\section{Therapeutic Closing}

The structure of mundane closing can be seen as primordial scene (Schegloff, 1996) for therapeutic closings, and coincidentally a therapy is distinct from everyday talk. To analyze therapeutic interaction, there are some constraints to be considered, for example that both participants need to have pragmatic knowledge (Peräkylä \& Vehviläinen, 2003) about the specific institutional genre - that is different for therapist and patient. The resulting communicative asymmetry implicates a dilemma. A closing element opens up and conducts the end of a movement in a musical performance, just as the therapeutic dyad has to 'strike the right chord' in closing, that is why, I will refer to this problem as the coda dilemma: How can the encounter with open topics be closed down in a therapeutic helpful way? The therapist has to ensure the rules of therapeutic interaction. So the therapist has to unilaterally open up the closing sequence, though the patient might have open topics or "unmentioned mentionables" (Schegloff \& Sacks, 1973, p. 303) and because "professionals lack the epistemic authority" (Stommel \& te Molder, 2015, p. 284) to ensure that the actual encounter can though be closed down, both, therapist and patient, need to negotiate the process of closing as an "interactional achievement" (Schegloff \& Sacks, 1973, p. 290). On the one hand, topicalization of unmentioned mentionables in the process of closing therapeutic encounters is dispreferred and on the other hand the therapist needs the patient to actively co-work on the conduct of closing. How do interlocutors conduct the closing procedure and which communicative techniques do they apply to solve the coda dilemma?

\section{Types of Therapeutic Closing}

The over-all structure of therapy reveals some answers to the question of communicative techniques analyzable on a micro-level: I found three different closing types with different frequencies (see Figure 3$)^{2}$. All in all there are 13 compact $(2-4-7)^{3}, 9$ stretched $(3-4-2)$ and 6 commented $(4-1-0 ; 1)$ closings. First the compact style is characterized by

2 On the $\mathrm{x}$-axis there is visualized time and on the y-axis there is the frequency. There are three columns, for the first, the second and the last third of the therapy. Each column consists of 9 closing sessions, whereby green stands for compact, red for stretched and orange for commented closing types.

3 This format displays the frequency in the segments of this therapeutic over-all process: (1st third-2nd third-3rd third). The last session is separatedly attached by a semicolon.

Language and Psychoanalysis, 2016, 5 (2), 46-61 
its compact way of dealing with insertions, like arrangements, linking to next session, complaint remedies or re-open topic talk (see Example 1). By contrast, stretched closings deal with insertions in an extensive way (see Example 2). Commented closings extend the actual encounter after the terminal exchange (see Example 3). Comparing all of the 28 sessions, one result is that the appearance of the different closing types is related to the process of therapy: While the commented type decreases from beginning to end, the compact type increases.

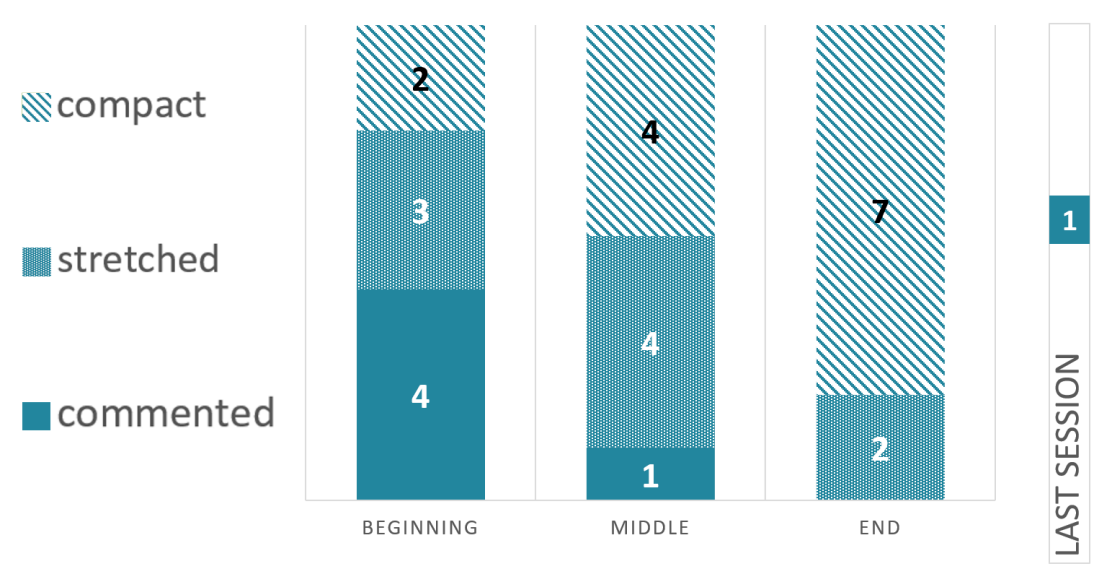

Figure 3

Types of closing (frequency)

The three types of closings can be seen as manifest realizations of an implicit communicative problem, the coda dilemma. To ensure that the actual encounter can be closed down, though there are unmentioned mentionables, both, therapist and patient, coconstruct the closing sequence typically by evaluating the therapeutic process so far, what I call Joint Evaluation of Therapeutic Help (JETH). This evaluative solution corresponds with the function of mundane preclosings and is understood as in-session qualification done by the participants themselves in their orderly interaction (Schegloff \& Sacks, 1973, p. 290) ${ }^{4}$. In the material these small evaluative elements locally handle the coda dilemma in an affiliative way either as JETH type 1) unilaterally offered or 2) interactively performed.

Transcriptions of closing sequences are analyzed in three procedural categories: i) mutually calibrated steps of closing, following the minimal scheme proposed by Schegloff and Sacks (1973), as a process of Joint Activity (f.e. see Clark, 2006), ii) expressing an "informational imperative" (Enfield, 2006, p. 399) or (Un-)Common Ground as a certain closing type (compact, stretched or commented) and iii) affording a particular degree of an "affiliative imperative" (ibid.) or Joint Commitment as JETH type

4 The authors describe that orderly interactions "were produced so as to allow the display by the coparticipants to each other of their analysis, appreciation, and use of that orderliness" (ibid.).

Language and Psychoanalysis, 2016, 5 (2), 46-61

http://dx.doi.org/10.7565/landp.v5i2.1560 
(1: unilateral offer or 2: interactional performance). Like reading a clavier excerpt there must be known some transcript notes:

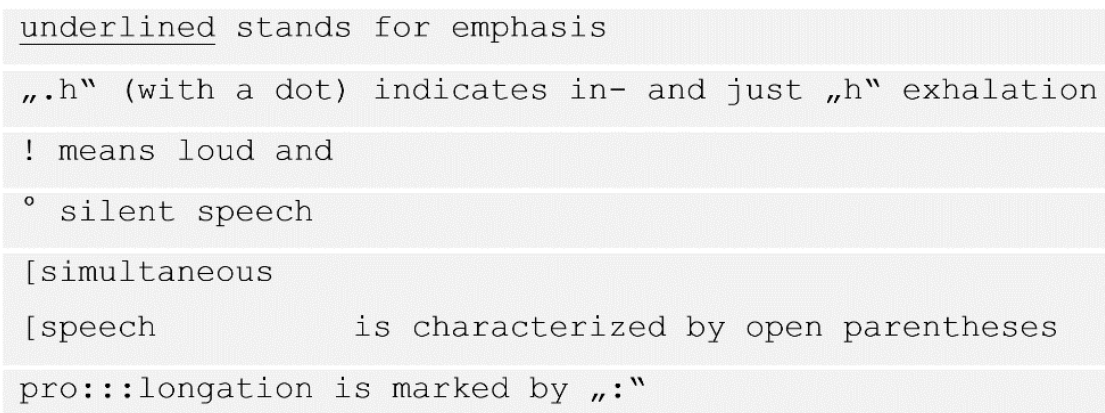

\section{Figure 4}

Transcript Notes

\section{Example 1: Compact Style}

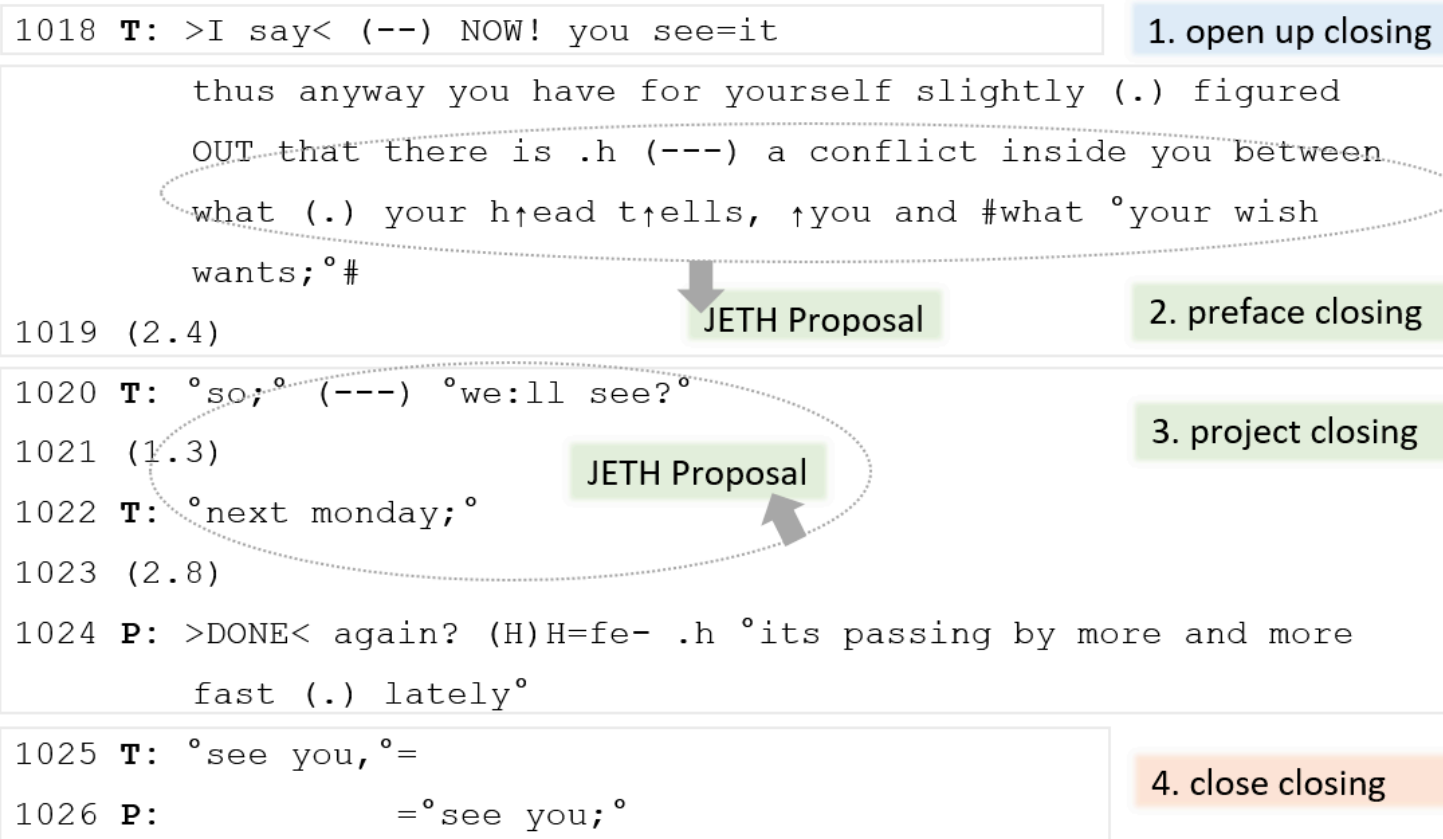

\section{Figure 5}

Transcript of closing sequence of session 10

This first example is a compact closing with two JETH as unilateral offers. An intermission of two weeks, when the therapist has been in another country, preceded this tenth session. Just before this sequence the interlocutors deal with the 'display of interest' by asking questions or staying silent. 
The therapist unilaterally opens up the closing sequence with a prosodic boundary marker ("NOW!") that differentiates the prior talk from what follows. As gatekeeper" (Erickson \& Shultz, 1982) of therapeutic rules he continues to preface closing (see end of line 1018) with an "upshot" (Button, 1987). Generally spoken, an upshot's function is understandable as expression of "deontic authority" (Searle, 1995), that is to interactionally co-produce authority that is dependent on confirmation of the other (Stevanovic \& Peräkylä, 2012). With these deontic means the therapist makes relevant the patient's reaction. The upshot's second, specific functional aspect is a possible preclosing, that what is said until now, can be confirmed in the upshot's sequential position to close the prior topic or to take the upshot's insight as a proposal for elaboration. This concluding remark can be heard as a proposal for the other to co-evaluate the session, represented by the upshot, and therefore an upshot in the end of the encounter is a JETH proposal, and the following pause a Turn Relevant Place (TRP). It is remarkable, that the patient (in line 1019) does not react and does not say whether he has something to say or not. The sequential order of talk makes visible how 'doing communicative resistance' is done. This is a Typical Problematic Situation (Buchholz, 2016), because it was found that pauses up to approximately three seconds (Frankel, Levitt, Murray, Greenberg, \& Angus, 2006) indicate a pause for reflection while longer pauses mark a communicative rupture (Safran \& Muran, 2000) in the "interaction engine" (Levinson, 2006). A challenge for the interactants is to paradoxically repair the interaction engine to set the stage for closing down the mutual orientation towards interaction.

The therapist places again a boundary marker ("oso;") what conversationally functions

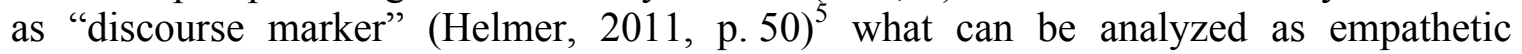
towards the recipient, because it i) reverts to common ground and ii) connects the prior turn (not the previous topic) with the actual one and thereby routes the other's expectations that a topic shift might follow. Closing is projected by the therapist who connects the actual with the following encounter ("we:1l see?" "next monday;") by proposing JETH through an "arrangement" (Button, 1987, p. 104). This creates a "closing-relevant" (Schegloff \& Sacks, 1973, p. 306) or "strongly closing implicative" (West, 2006, p. 386) environment: on the one hand arrangements open up a potentially new topic, and on the other hand the communication of a next encounter stresses that there is nothing more to say, because the interlocutors do not add new aspects to prior talk and therefore co-orientate towards taking leave. The first time in this sequence the patient actively participates (1024), but not does not confirm the second JETH as a future activity proposal. By loudly breathing out and placing a glottal stop ("( $\mathrm{H}) \mathrm{H}=\mathrm{fe}-$-") the patient sites a "misplacement marker"6 (Schegloff \& Sacks, 1973, p. 320).

Thereby the patient communicates the therapist how to interpret his utterance: as not being sequentially connected to the prior closing sequence or what the therapist just said

\footnotetext{
${ }^{5}$ Helmer 2011 analyzes german 'also' as a discourse marker that produces cohesion between one and another turn and thereby is a reference for "intersubjectivity" (ibid., p. 51).

${ }^{6}$ Misplacement marker can be understood as "an orientation by their user to the proper sequential-organizational character of a particular place in a conversation, and a recognition that an utterance that is thereby prefaced may not fit, and that the recipient should not attempt to use this placement in understanding their occurrence" (ibid.).

Language and Psychoanalysis, 2016, 5 (2), 46-61

http://dx.doi.org/10.7565/landp.v5i2.1560
} 
before. The patient's expression of 'misplaced surprise' connects to what was described afore as 'doing communicative resistance' (1019), because he explicates that he likes to extend topic talk and does not want to move towards closing. Coincidental opposing projects (Alder, Brakemeier, Dittmann, Dreyer, \& Buchholz, 2016) in the conduct of closing are i) what can be interpreted as the patient's 'active-passive mode' or hands-off approach of cooperation (see actively saying nothing, though it would be expectable in 1019; actively saying something, though it is not expectable: misplaced surprise in 1024) and ii) the therapist's consequent work on closing with deontic means, so to speak as a 'demonstration of coherence' (see boundary markers in 1018 and 1020; JETH proposals in 1018 and 1020-1022). The locally produced solution of the coda dilemma in this session is, that the patient cooperates in an active-passive mode while the therapist demonstrates coherence - leading to non-marked dispreference of topicalization of unmentioned mentionables: The prior turn of the patient is treated as non-relevant to the process of closing so that the therapist initiates the terminal exchange what is accepted by the patient who thereby closes down the encounter (1025-1026).

The tenth session i) consists of four distinct steps of closing (open up, preface, project and close closing section), ii) with a high "economy of expression" (Enfield, 2006, p. 399) or common-ground activities by cooperating in a compact way $^{7}$, iii) that is not yet highly affiliated interactionally, using two unilateral offers (JETH type 1) without explicit confirmation (neither: explicit disagreement) towards the proposals, marking a rather low level of Joint Commitment.

7 This minimal reactiveness on the coincidental opposing projects of the interlocutors can be analyzed as acting on a Common Ground of closing, insofar as both interlocutors deal minimally with the therapist's project of closing down, and with the patient's project of prolonging closing. The insertion of the patient (1.1024) for example is not treated as an "action formulation" (Thompson, Fox, \& CouperKuhlen, 2015, p.4), but as common knowledge as an "action in its own right" (Schegloff \& Sacks, 1973, p. 290). That is why the function of the patient's utterance is not a contentual expression of not knowing about closing, but a formal display of lacking interactional affiliation (having unmentioned mentionables or another communicative project than the therapist). 


\section{Example 2: Stretched Type}

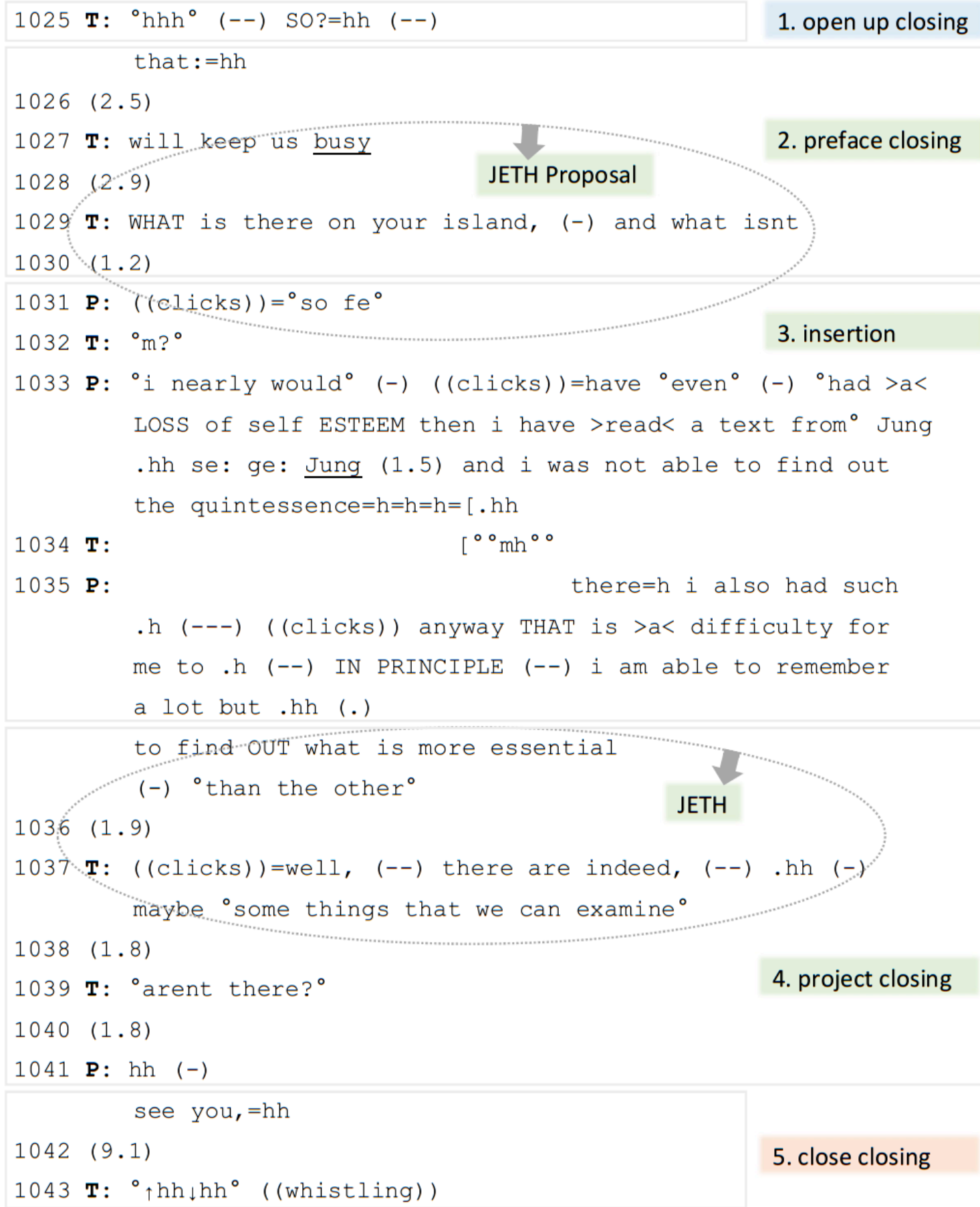

\section{Figure 6}

Transcript of closing sequence of session 12

The second example is a stretched closing with two JETH, first as an unilateral offer and second as an interactional performance. This session shows how the two participants deal 
with unmentioned mentionables inserted in the conduct of closing. The last topic is about the fantasy of being on an island. The therapist opens up closing by placing a prosodic boundary marker ("SO?") and conducts closing with a covert announcement ("will keep us busy" "WHAT is there on your island, (-) and what isn't") that is encased by three pauses $(1026 ; 1028$ and 1030). These pauses structure the conduct of closing as a process that needs to be differentiated from prior topic talk, because the expectancy of pauses as Transition Relevant Places (TRP) has to be transformed into conversational nonexpectancy of further talk. The preface of closing is not clearly understood as conversational non-expectancy by the patient's following unintelligible utterance (1031). This ambiguous turn initiates an insertion of patient-sided topic talk about dealing with

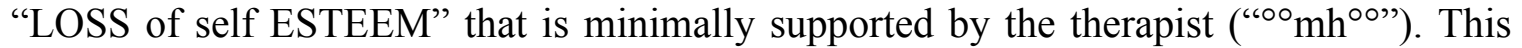
insertion stretches the conduct of closing, but it does not suspend the process as a whole. The communication of unmentioned mentionables is possible, but dispreferred in closing sequences, as can be seen in the next turn of the therapist who i) projects closing empathetically with "well" as a "face-threat mitigator" (Jucker, 1993) and ii) does not deepen further contents. The projection of closing is strengthened, because the therapist coherently links "osome things that we can examine" to what the patient said immediately before ("find OUT what is more essential (-) ${ }^{\circ}$ than the other"). This turn connection subsequently co-produces a project formulation, and therefore a JETH, created by sequential $^{8}$ and contentual ${ }^{9}$ coherence. The therapist increases the relevance of suspension of TRP by asking a question directly (1039), that is again encased by two pauses $(1038 ; 1040)$. This time it is understood as projection of closing and suspension of TRP, as we can see in the next turn of the patient who does not (actively) confirm that interactionally co-produced JETH, but (indirectly) accepts it by initiating the close of closing (1041). ${ }^{10}$

The twelfth session i) consists of five steps towards closing (open up, preface closing, insertion, project and close closing section), ii) expressing a medially economical information and expectation management or common-ground activities by cooperating in a stretched way ${ }^{11}$, iii) that is affiliated interactionally, using a co-produced project formulation as a Joint Commitment.

8 Sequential coherence is created by mitigating a potential face-threat after patient's topic talk and before therapist's non-topic talk.

${ }^{9}$ Contentual coherence is created by linking to patient's last said words.

${ }^{10}$ In relation to the missing second pair part (therapist's answer goodbye greetings), this closing sequence seems to be rather odd. But we have to recognize, that there is not assuredly no second pair part, because we do not see the therapist nodding, skaing hands, waving or performing a non-linguistic movement. Whatever we think that this ,index change' means, we have to stick methodologically to what we know from the interactant's reaction, and because this reaction is absent, it is this absent turn valuing the first one as none to react to.

${ }^{11} \mathrm{Re}$-open topic talk is dispreferred in the conduct of closing, and can be seen as an uncommon-ground activity, because the interlocutors structurally do not know about the other's open topics. Conversational consequence is that the patient has to learn about topicalization (in terms of dealing with asymmetric talk implications of having to know about which topics can be placed or re-opened at a certain time).

Language and Psychoanalysis, 2016, 5 (2), 46-61

http://dx.doi.org/10.7565/landp.v5i2.1560 


\section{Example 3: Commented Type}

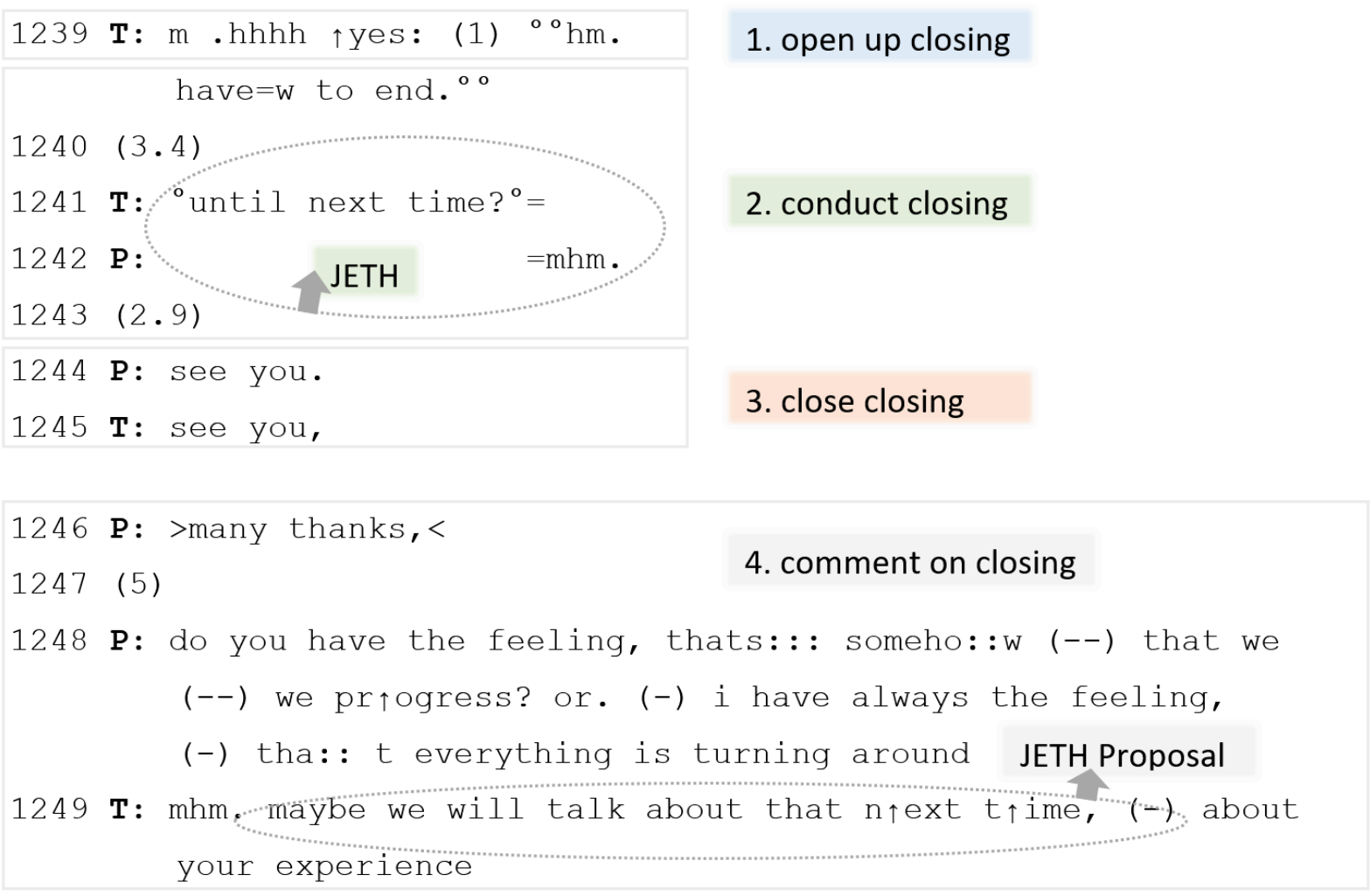

\section{Figure 7}

Transcript of closing sequence of session 03

The third session is a commented closing with two JETH first as an interactional performance and second as an unilateral offer. The last topic of this session is about tensions the therapist stresses when the patient talks about feelings while eating. The patient describes anger and contrasts possible expectations of being hindered by this anger in other situations as well, by saying that in total he was fine. Closing is opened up by the therapist who initiates the sequence with a coherent boundary marker (" $\uparrow$ yes:") and unilaterally verifies that there is nothing left to say ("hm."). This process of initiation and unilateral verification is accompanied by long inhaling (."hhhh") and declaration (pause of $1 \mathrm{sec}$.), that marks the following utterance as prolonged or misplaced (see Example 1) in terms of its sequential position, but coherent in terms of closing as an unit in its own right. Closing is conducted by the therapist who places an "overt announcement" (Button, 1987) and thereby directively works on projecting closing ("have $=\mathrm{w}$ to end."). The directive closing attempt of the therapist is a TPS that is a delicate communicative act: After a second rather long pause (see lines 1239 and 1240) the therapist projects closing by 'softening' the directive attempt ${ }^{12}$ with an "initiation

12 The therapist repairs his previous directive attempt and this 'softening' can be analyzed as empathetically modulation of the other's expectations and thereby affords "the patient's recognition of his own mind in the therapist's mind“ (Fonagy \& Allison, 2015, p. 2). 
action" (Thompson, Fox, \& Couper-Kuhlen, 2015, p. 4) that links to the next session ("ountil next time?").

This initiation action is the first part of JETH that i) asks for verification (assumingly that no unmentioned mentionables will be risen), ii) increases the relevance of active cooperation, who is encouraged to answer the interrogative pre-turn of the therapist ${ }^{13}$ and iii) connects the actual with the upcoming encounter. The second part of the JETH is the verification by the patient ("mhm."). After a third rather long pause (2.9) the interactants exchange goodbye greetings (1244-1245). Techniqually seen, the patient's next turn reopens a new (topic) talk, that is why we can understand this postsession time as comment on the previous talk. To open up closing in a directive way needs to be expressly consented to. A seemingly harmless question ("do you have the feeling, thats::: someho::w (--) that we (--) we pr个ogress?") is placed by the patient, what is called "bythe-way syndrome" (West, 2006, p. 380): the placement of important concerns in the postsession time en passant. Interestingly, the speaker addresses the hearer's feelings, what can be analyzed as a connection to the last topic (of anger as a by-the-way feeling). This connection re-opens a topic, but "why that now" (Schegloff \& Sacks, 1973, p. 299)?

The communicative functions of the patient's comment on the previous closing process is to mention unmentioned concerns connected to the last topic, that he himself can not solve, what is conversationally indicated by tying back the topic on himself ("i have always the feeling, (-) tha::t everything is turning around"). Through this "complaint remedy" (Davidson, 1978), formulated as metaphorical dizziness that could be treated, the patient positions himself as needy and the therapist as help giving. That is what was called "reverse projects" (Alder et al., 2016): The patient's trial to establish these communicative roles can be seen as contrary towards the therapist's project of closing down the session, because to elaborate on the complaint remedy means to continue the therapeutic interaction. The therapist reacts conversationally clever while stressing i) the

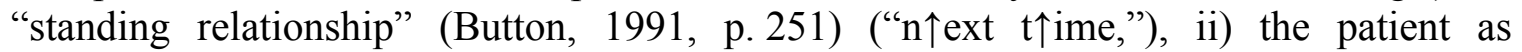
communicative competent agent of talk ("your experience"), iii) closing again as an unit ist own right, while not deepening the re-opened topic and iv) therefore solving the coda dilemma locally by placing a JETH proposal ("maybe we will talk about that $\mathrm{n} \uparrow$ ext t个ime,").

The third session i) consists of four steps towards closing (open up, project, close and comment the closing section), ii) expressing a high economical information and expectation management or common-ground activity by cooperating in a stretched way, iii) that is affiliated interactionally, using a co-produced project formulation, marking a Joint Commitment.

13 Interestingly, the therapist does not ask a question like "do we see us next time?," but places a risingly intonated formulation, that implies that both participants know about the upcoming meeting; we can assume they both know the date, the time and the place. With that said, epistemic knowledge is clear: it is not about negotiation of a possibly not happening next encounter, and the therapist's utterance is not understandable as 'real' appointment, but as a functional linking of the actual with the following session.

Language and Psychoanalysis, 2016, 5 (2), 46-61

http://dx.doi.org/10.7565/landp.v5i2.1560 


\section{Conclusion}

There are two structural different consequences that can be subtracted out of this study of closings, that are 1) methodological and 2) practical - leading to "situationism" (Buchholz, 2016). There is a methodological consequence, to analyze the material as if we look through a prism that refracts the light threefold, describing practices of i) Joint Activity consisting of distinct steps of closing (see Figure 8 - Scheme of Closing), ii) with different degrees of economy of expression (see Figure 3 - Types of Closing: high/compact, medially/stretched or low/commented) and iii) with unilateral or Joint Commitments as a display of interactional affiliation (see JETH as joint project formulation).

This differentiation allows us to understand the three closing sequences as reciprocal actions established by Common-Ground Activities and Joint Commitments: the first example consists of four steps performed in a compact way, expressing high Common Ground-Activities, that are interactionally disaffiliated, the second example realizes in five steps a stretched closing style with a medially economical information and expectation management, that is interactional affiliated and the third example again accomplishes closing in four steps in a commented manner with Uncommon-Ground Activities, that are interactional affiliated. The participants deal with differences in their common knowledge about i) when to place an utterance ("Kairos" Erickson \& Shultz, 1982, p. 72), ii) how long a session is ("Chronos," ibid.) and iii) what topics are allowed in a closing sequence.

The three closing types reflect that information management: the compact style is a very economical expression of information management, the stretched style has common and uncommon shares or parts and the commented style expresses resistance against the communicative process of closing and therefore is an Uncommon-Ground activity. On the other hand, the interaction needs commitments towards a Joint Action, what manifests itself in affiliative evaluations that can be co-productions or unilateral proposals. Insofar the distinction between Common-Ground Activities and Joint Commitments can be fruitful for clinicians to understand closing of therapeutic encounters as a situation with 'audible' steps, indicating a process in closing and therapy en bloc instead of a stable construct. 


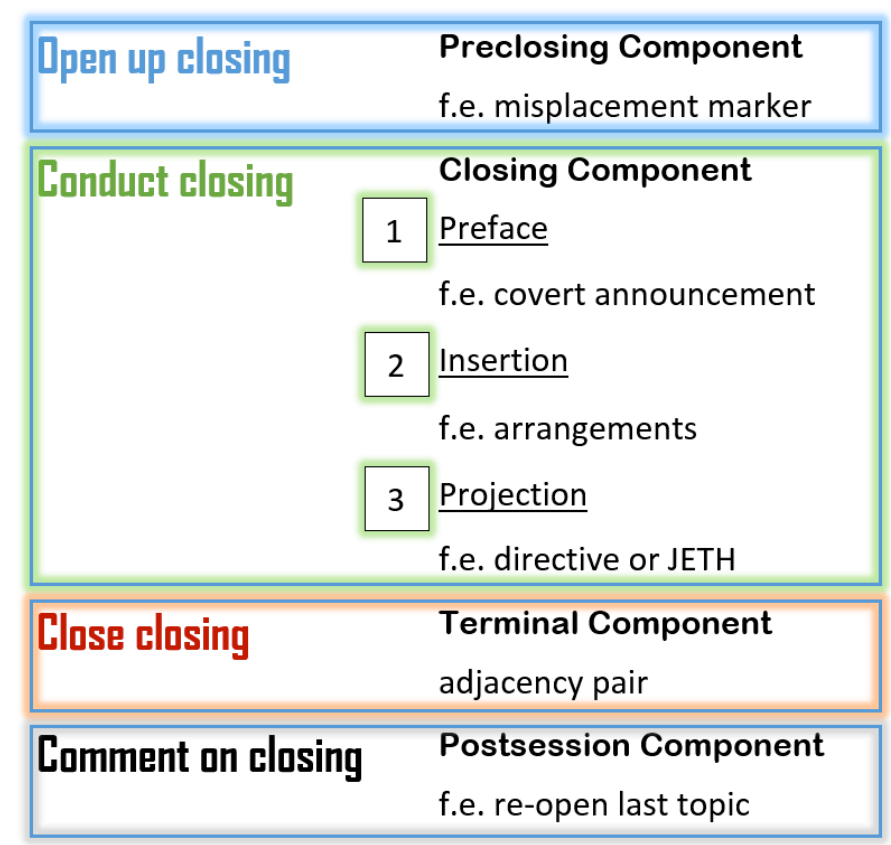

Figure 8

Scheme of closing

The Scheme of Closing is induced from 28 closing sequences and expresses an over-all structure of commitments towards the therapeutic closing process. There are up to six sequences that are co-constructed consecutively. Like two people assemblying a table through cooperation (Clark, 2006, p. $127 \mathrm{ff}$.), the participants commit towards closing as a Joint Action, that needs to be accomplished stepwise. Following practices are taken from the Scheme of Closing as clinical relevant learnings:

1. While there is a mutual verification of unmentioned mentionables in mundane conversations (Schegloff \& Sacks, 1973), one finding of this study is, that the therapist as the "gatekeeper" (Erickson \& Shultz, 1982) in most of the time initiates closing section unilaterally. By unilaterally open up closing, the speaker "reduces" expectancies from mundane preclosing procedure, whether something is left to say. This reduction practice is described by Clayman $(1989$, p. 685) as "sequential deletion of practice at junctures where, in ordinary conversation, they would be relevant and expectable". Preclosings as 'hinges' between topic talk and closing component do not allow reinvocations of new topics (Hartford \& Bardovi-Harlig, 1992, p. 97; "preclosing questions fail as a closing device" at Stommel \& te Molder, 2015) what is different to Schegloff and Sacks show it for everyday talk. This process supports the insight, that therapists should "help patients raise new problems early" (White, Rosson, Christensen, Hart, \& Levinson, 1997, p. 165).

2. This communicative strategy expresses that the function of preclosings, to evaluate the readiness for closing, in therapeutic talk is not done through answering preclosing questions, but through unilaterally open up and preface closing therapist-sided. That is one reason why therapeutic interaction is to be Language and Psychoanalysis, 2016, 5 (2), 46-61 
called communicative asymmetric. But as Lakoff (1980, p. 11) puts it, "the one who appears to hold the power does not hold it": the therapist has deontic authority only and his action is subject to approval. With that said, i) it was found to be helpful for prefacing closing to give a summary or upshot of the session as an "orientation statement" (White et al., 1997, p. 165) and ii) the conduct of closing is due to two important consequences: to hold ready a slot, first, to reopen topic talk (insertion), for example by asking "anything else?" (ibid.) or to place a typical last topic like an arrangement and, second, to co-evaluate the session so far (to project closing). While the preface increases the relevance for closing, the projection constricts possible expectations of re-open topic talk. Repeated JETH proposals (see Example 1) seem to be helpful to work towards closing.

3. The projection can connect to future encounters understandable as "continuity of care" (West, 2006, p. 415) and creating a "standing relationship" whereby the participants "elaborate upon it and constitute it as relevant for their talk and conduct, in their talk and conduct" (Button, 1991, p. 272). Therapeutic techniques to project closing are Joint Evaluations of Therapeutic Help (JETH) or active linking to next session.

4. To deal with expansion after closing not only as patient-sided maladaptive action, but as a comment on the situation, that, if taken into conversational account, affords the opportunity to work on the communicative resistance with communicative means - accessible for both participants.

Besides contentual deliberations 'why' the patient acts in a certain way, Conversation Analysis stresses reflections on formal and functional aspects, the 'how' of conduct of interactions This how is described by JETH that functions as i) postprocessing of the collaboration of the actual session and ii) preparation of possible following encounters. These characteristics open a chance for the therapeutic dyad 'moving closer' by ritually working on the social relationship. But it is a skilful act to close the actual encounter as expression of collaboration of two communicative competent interlocutors and at the same time giving a push to the necessarity of further treatment. To dare to walk this tightrope can succeed by drawing on interactive resources, instead of highlighting individual indigence. This interaction requires courage, because, in dyads, both interlocutors commit towards an active contribution, that can be claimed and evaluated mutually. 


\section{References}

Alder, M.-L., Brakemeier, E.-L., Dittmann, M. M., Dreyer, F., \& Buchholz, M. B. (2016). Fehlleistungen als Empathie-Chance: Die Gegenläufigkeit von "Projekten" der Patientin und der Therapeutin. Psychotherapie Forum, 21 (1), 2-10.

Buchholz, M. B. (2016). Conversational errors and common ground activities in psychotherapy: Insights from conversation analysis. International Journal of Psychological Studies, 134, 134-154.

Button, G. (1987). Moving out of closings. In G. Button \& J. R. E. Lee (Eds.), Talk and social organisation (101-151). Clevedon, UK: Multilingual Matters.

Button, G. (1991). Conversation-in-a-series. In D. Boden \& D. H. Zimmerman (Eds.), Talk and social structure. Studies in ethnomethodology and conversation analysis (pp. 251-277). Cambridge, UK: Polity Press.

Clark, H. H. (2006). Social actions, social commitments. In N. J. Enfield \& S. C. Levinson (Eds.), Roots of human sociality. Culture, cognition and interaction (pp. 126-150). New York, NY: Berg.

Clayman, S. E. (1989). The production of punctuality: Social interaction, temporal organization, and social structure. American Journal of Sociology, 95, 659-691.

Davidson, J. (1978). An instance of negotiation in a call closing. Sociology, 12 (1) 123133.

Enfield, N. J. (2006). Social consequences of Common Ground. In N. J. Enfield \& S. C. Levinson (Eds.), Roots of human sociality. Culture, cognition and interaction (pp. 399-430). Oxford, New York, NY: Berg.

Erickson, F., \& Shultz, J. J. (1982). The counselor as gatekeeper: Social interaction in interviews. Orlando, FL: Academic Press.

Fonagy, P., \& Allison, E. (2015). Psychic reality and the nature of consciousness. International Journal of Psychoanalysis, 97, 1-20.

Frankel, Z., Levitt, H. M., Murray, D. M., Greenberg, L. S., \& Angus, L. (2006). Assessing silent processes in psychotherapy: An empirically derived categorization system and sampling strategy. Psychotherapy Research, 16, 627-638.

Hartford, B. S., \& Bardovi-Harlig, K. (1992). Closing the conversation: Evidence from the academic advising session. Discourse Processes, 15, 93-116.

Helmer, H. (2011). Die Herstellung von Kohärenz in der Interaktion durch Turnanschlüsse mit dann. Mannheim, Germany: Verlag für Gesprächsforschung.

Holmes, J. (1997). 'Too early, too late': Endings in psychotherapy - an attachment perspective. British Journal of Psychotherapy, 14, 159-171.

Jucker, A. H. (1993). The discourse marker well: A relevance-theoretical account. Journal of Pragmatics, 19, 435-452.

Lakoff, R. T. (1980). Psychoanalytic discourse and ordinary conversation. Interfaces, 8, 2-7.

Levinson, S. C. (2006). On the human "interaction engine.” In N. J. Enfield \& S. C. Levinson (Eds.), Roots of human sociality. Culture, cognition and interaction (pp. 39-69). New York, NY: Berg.

Peräkylä, A., \& Vehviläinen, S. (2003). Conversation analysis and the professional stocks of interactional knowledge. Discourse \& Society, 14, 727-750.

Raitaniemi, M. (2014). Die Beendigung von finnischen und deutschen Telefonaten. Eine interaktionslinguistische, kontrastierende Untersuchung (Finnische Beiträge zur Germanistik, vol. 31). Frankfurt, M.: Lang Ed. 
Safran, J. D., \& Muran, J. C. (2000). Negotiating the therapeutic alliance: A relational treatment guide. New York, NY: Guilford Press.

Schegloff, E. A. (1996). Issues of relevance for discourse analysis: Contingency in action, interaction and co-participant context. In Computational and conversational discourse (pp. 3-35). Berlin: Springer.

Schegloff, E. A., \& Sacks, H. (1973). Opening up closings. Semiotica, 8, 289-327.

Searle, J. R. (1995). The Construction of Social Reality. New York, NY: Free Press.

Stevanovic, M., \& Peräkylä, A. (2012). Deontic authority in interaction: The right to announce, propose, and decide. Research on Language \& Social Interaction, 45, 297-321.

Stommel, W., \& te Molder, H. (2015). Counseling online and over the phone: When preclosing questions fail as a closing device. Research on Language and Social Interaction, 48, 281-300.

Thompson, S. A., Fox, B. A., \& Couper-Kuhlen, E. (2015). Grammar in everyday talk: Building responsive actions. Cambridge, UK: Cambridge University Press.

West, C. (2006). Coordinating closings in primary care visits: Producing continuity of care. In J. Heritage \& D. W. Maynard (Eds.), Communication in medical care. Interaction between primary care physicians and patients (pp. 379-415). Cambridge, UK: Cambridge University Press.

White, J. C., Rosson, C., Christensen, J., Hart, R., \& Levinson, W. (1997). Wrapping things up: A qualitative analysis of the closing moments of the medical visit. Patient Education and Counseling, 30, 155-165. 